\title{
El tiempo histórico del primer constitucionalismo en el Atlántico hispano. Balance y perspectivas ${ }^{1}$
}

The Moment of the Early

Constitutionalism in the Spanish

Atlantic. Historiographical Evaluation

and Perspectives

\section{José María Portillo Valdés \\ Profesor titular de Historia \\ Contemporánea en la Universidad \\ del Pais Vasco (UPV-Viscaya/España) \\ y catedrático de la Universidad \\ Externado de Colombia (Bogotál \\ Colombia). \\ e-mail:portival@gmail.com}

\begin{abstract}
Resumen
Terminando el año bicentenario de la constitución de Cádiz y cumplidos ya los del inicio de la independencia en buena parte de los países hispanoamericanos, este artículo hace balance historiográfico. Se pregunta, en primer lugar, en qué ha cambiado nuestro conocimiento acerca del proceso de disolución imperial y de conformación del primer constitucionalismo. En una segunda parte, apunta algunas rutas que podrian ser seguidas por la historiografía para explorar problemas que aún no están resueltos.
\end{abstract}

\section{Abstract}

During the last two years Latin American countries and Spain celebrated the bicentennial of the beginning of independence movements and the first modern constitutions, including the constitution of Cadiz (1812). This article evaluates the progress of our historiographical knowledge on this period during the last two decades. On the other hand, explores new possible paths to be followed in the forthcoming years in order to improve our knowledge of the experience of modernity in the Spanish Atlantic.

Palabras-clave
primer constitucionalismo, Atlántico hispano, liberalismo, independencia

Keywords

Early constitucionalism, Spanish Atlantic, liberalism, Independence más reducida se publica también en la revista Argentina de debate PolHis. 
2

GUERRA, François-Xavier, ANNINO, Antonio y LEIVA, Luis Castro (ed.). De los Imperios a las naciones: Iberoamérica. Zaragoza: Ibercaja, 1994.
Desde hace cuatro años venimos celebrando algunos bicentenarios de acontecimientos que marcaron de manera trascendental el espacio del Atlántico euroamericano. En efecto, hemos asistido a un estado de permanente celebración comenzando con el cumplimiento en 2008 de los doscientos años de la eclosión de la crisis que dio inicio a la descomposición de la mastodóntica monarquía española, pasando por los doscientos años, en 2010, del inicio de movimientos políticos que conducirían años después a la independencia a México, Argentina y otras repúblicas, así como, en 2011, de la primera declaración de independencia de un territorio de la monarquia (Venezuela) y llegando, finalmente, en 2012 al cumplimiento también de los doscientos años del intento más consistente de recomposición de la monarquía imperial española en forma de nación soberana (Cádiz). Todo ello, además de para dejar exhausta a buena parte de la academia, ha servido para incentivar en las últimas dos décadas nuestro conocimiento de esos trascendentales años.

No sólo sabemos -como cabía esperarse - mucho más sobre ese momento sino que, sobre todo, podemos hacer preguntas mucho más precisas sobre el mismo. Desde que un destacado grupo de historiadores publicó, hace casi veinte años, un volumen, que puede entenderse como the state of the art entonces, hasta hoy ciertamente nuestro conocimiento del momento en que surgió el constitucionalismo en el espacio antes ocupado por la monarquía española se ha sofisticado notablemente. ${ }^{2}$ Sin embargo, a pesar del gran aporte historiográfico realizado en estos años sobre el momento que siguió a 1808, son varias las cuestiones esenciales acerca del mismo que precisan de análisis y debate.

En este texto propongo valorar algunas de las carencias que, a mi entender, aún presenta nuestro conocimiento de aquellas primeras manifestaciones del constitucionalismo en el área atlántica hispana ( $y$, aunque no lo conozca ni mucho menos tanto, creo no equivocarme mucho si afirmo que también en la luso-brasileira). Aunque pueda parecer paradójico, considero que un primer flanco débil en el debate historiográfico es el que debería determinar precisamente el estatuto del primer constitucionalismo dentro de la historia constitucional. Una segunda serie de cuestiones tiene que ver con los elementos que hacen singular al constitucionalismo en el espacio atlántico hispano cuando consideramos este proceso desde una perspectiva más global. La tercera consideración que quisiera introducir, porque considero que puede reorientar nuestra valoración general del primer constitucionalismo, consiste en la relevancia de su textualidad y la necesidad de buscar aquel constitucionalismo más allá de los textos, apuntando a formas difusas de jurisprudencia constitucional.

La primera de las cuestiones aludidas tiene que ver con la forma en que situamos la historia del primer constitucionalismo en el espacio de la historia constitucional. Hemos dado siempre por supuesto que aquellas primeras manifestaciones constitucionales formaban una unidad con la historia de las constituciones que llega hasta nuestros dias. Cualquier manual de historia constitucional que tomemos como referencia nos mostrará, en clave nacional, un recorrido que va desde aquellos primeros textos hasta los más recientes presentando toda esa unidad como la Historia constitucional de tal o cual nación. Es algo que ni se discute, porque si afirmáramos que el primer constitucionalismo no forma parte de la unicidad de la historia constitucional estariamos poco menos que sosteniendo que el 
3

Aunque los datos ahí están: HERREJÓN, Carlos. Hidalgo: maestro, párroco, insurgente. México-DF: Banamex, 2011. Esta apreciación puede generalizarse constatando cuántos estudios se han dedicado al pensamiento reaccionario, a las propuestas de continuidad o a la "visión de los vencidos" en comparación con los que llevan como divisa el estudio de la revolución, la modernidad y el liberalismo. VEJO, Tomás Pérez. Elegía criolla. Una interpretación de las guerras de independencia hispanoamericanas. México-DF: 2010. Una muestra de la pertinencia de prestar atención a esas manifestaciones no tan a tono con la historia oficial en ALÓS, Javier López. Entre el trono y el escaño. Madrid: Cortes Generales, 2011. estudio de aquel período inicial del constitucionalismo pertenece a otra disciplina diversa de la historia constitucional propiamente dicha.

Sin llegar a tanto, es decir, entendiendo que el primer constitucionalismo sí forma parte de la unicidad de la historia constitucional, uno de los propósitos de este texto es abrir una reflexión sobre la necesidad de marcar algunas discontinuidades que existen entre aquella forma de constitucionalismo y la historia constitucional que corre desde el liberalismo hasta hoy. En cierto modo se trata de matizar la aproximación tan habitual desde la politología y buena parte de la historiografía a los orígenes del constitucionalismo como el momento de partida de un experimento político que forma unidad con el liberalismo, con su reinvención constitucional desde los años veinte del siglo pasado que, tras el devastador paso de la II Guerra Mundial, Ilega a la actualidad. Sin negar, repito, la unicidad de la historia constitucional creo que conviene no absolutizarla hasta el punto de no poder ver la condición específica del primer constitucionalismo como un tiempo distinto al del constitucionalismo liberal. Esto es especialmente cierto para el caso de los territorios que experimentaron la crisis de la monarquía española entre 1808 y 1825.

Lo habitual, sin embargo, es entender que aquel constitucionalismo primigenio originó él mismo el liberalismo en el espacio del Atlántico hispano. Bajo rubro que haga referencia a "orígenes" y "liberalismo" se suele arrancar por presentar a las primeras manifestaciones constitucionales surgidas ante la crisis de 1808. Es la lógica que organiza también las especialidades académicas de Historia. En América usualmente como una distinción frente al período "colonial" y para resaltar el propiamente "nacional" y en España como una línea de separación entre la época moderna y la contemporánea. En varios de nuestros archivos nacionales puede, sin embargo, verse cómo el material histórico se resiste a este encasillamiento estableciendo un momento indetminado entre "colonia" y "república". Si prescindimos por un momento del mimetismo que existe en esta distinción académica respecto de la visión francesa de regímenes antiguo y moderno divididos por la revolución de 1789, lo relevante es que entendamos que nos es contemporáneo aquel primer constitucionalismo. Eso es lo que se significa cuando se asume que con aquellas constituciones comenzó un tiempo histórico que nos envuelve también en nuestro presente.

Esta comprensión ha conducido a un análisis de aquel periodo en que la monarquía hizo crisis y el constitucionalismo surgió como respuesta a la misma, que se ha centrado mayoritariamente en el novum. La historiografía se ha escorado muy claramente desde el siglo XIX hacia el señalamiento de los aspectos de lo que se entendía "moderno" y que vinieron de la mano de los acontecimientos que siguieron a la crisis de 1808. No es que haya estado totalmente ausente la llamada de atención sobre la presencia de lo tradicional o incluso de lo "anti-moderno" en los debates y productos politicos de esas décadas, pero el sentido general del interés historiográfico ha estado apuntando mucho más claramente a la novedad que a la continuidad. Por poner sólo un ejemplo, resultaría difícil encontrar un estudio que pondere el peso que en la acción de Miguel Hidalgo tuvo un pensamiento que se asentaba mucho más sobre una determinada interpretación de la tradición que sobre el novum de la modernidad. ${ }^{3}$

Si bien la historiografía - al menos la académica - es bien consciente de que no todo fue un iter recorrido en derechura hacia la modernidad liberal y de que los propios currículums de los próceres del momento tienen 
4

BREÑA, Roberto. El imperio de las circunstancias (Las independencias hispanoamericanas y la revolución liberal española). Madrid: Marcial Pons/El Colegio de México, 2012. cap.7.

5

CHIARAMONTE, José Carlos. Nación y Estado en Iberoamérica. El lenguaje político en tiempos de la independencia. Buenos Aires: Editorial Sudamericana, 2004.

6 VIEJO, Julián. Caridad, amor propio y pasiones en la monarquía hispana a finales del siglo XVIII. Historia y Política, n.19, 2008.

7

Muy evidente, por ejemplo, en el caso de Álvaro Flórez Estrada, quien comenzó asi su introducción para una historia de la revolución de España: "La revolución de Francia, acaecida veinte años hace, y cuyos efectos son actualmente más sensibles...": ESTRADA, Álvaro Flórez. Introducción para la Historia de la Revolución de España. Londres: R. Juigné, 1810. p.11.

8

Y esto desde las primeras interpretaciones que se hicieron sobre la marcha de las propias revoluciones: ANNINO, Antonio y ROJAS, Rafael. La independencia. Los libros de la patria. México- DF: FCE, 2008; MEJIA, Sergio. La revolución en letras. La Historia de la Revolución de José Manuel Restrepo (1781-1863). Bogotá: Universidad de los Andes, 2007. sombras alargadas que cubren parte de sus gloriosas luces, lo cierto es que globalmente la pauta interpretativa ha venido claramente marcada por la asimilación del momento que va de 1808 a la consolidación republicana como el equivalente a la revolución que en otros escenarios del hemisferio occidental estaba teniendo lugar desde 1776. Es por ello que en los últimos años hemos tendido a incorporar estos sucesos históricos dentro de un mainstream dominado por la idea de "revoluciones atlánticas". Aunque en puridad las ibéricas serían las únicas revoluciones realmente atlánticas, la crítica a la aplicación del modelo es perfectamente pertinente porque permite, creo, singularizar estos procesos en una época de revoluciones. ${ }^{4}$

En efecto, las revoluciones que se dieron en el área hispana conformaron, sin duda, parte del tema general de las revoluciones atlánticas, pero lo hicieron como una declinación particular que partía también de una muy particular lectura de la filosofía política moderna. ${ }^{5}$ Aunque no es cuestión que se pueda desarrollar aquí con la debida atención, baste decir que el pensamiento más interesado por la modernidad en el ámbito de la monarquía católica tuvo que realizar notables esfuerzos intelectuales de lectura y adaptación de aquella filosofía a una Weltanschaaung católica. Esto último tuvo un muy significativo motivo de reflexión en todo lo que concernía a los atributos del individuo moderno (libertad de conciencia, autonomía, interés, amor propio, razón natural de sus derechos, etc.). ${ }^{6}$

Aunque sólo fuera por ese dato de una aproximación peculiar a la filosofía moderna, ya deberíamos estar sobre aviso de las diferencias que en el momento de las revoluciones se podrian abrir entre unos espacios y otros del hemisferio occidental. Por ello una crítica del empaquetamiento conjunto de estas revoluciones con las de EEUU y Francia en unas "revoluciones atlánticas" puede corregir una tendencia a la asimilación entre los distintos momentos revolucionarios del hemisferio occidental. Y téngase presente que la tendencia a asimilar las revoluciones hispánicas a la revolución norteamericana y, sobre todo, a la revolución francesa comenzó prácticamente en el momento en que se estaban produciendo ${ }^{7}$. En efecto, los años que, dependiendo del gusto nacional, se eligieron como referencia esencial (así por ejemplo 1808 en España, 1810 en México, Argentina, Colombia, 1811 en Venezuela o 1825 en Bolivia) se entendieron por la historiografía nacional respectiva como particulares mil setecientos ochenta y nueves ${ }^{8}$. Independencia y constitución vendrian a marcar el momento de aporte propio a una historia de la revolución del hemisferio occidental que venía cambiando el curso de la Historia.

Siguiendo el imperativo de este pensamiento historiográfico, se trataba de ubicar en ese momento de crisis y revolución los signos de una modernidad a la que, así, quedaban acoplados los distintos espacios nacionales resultantes: declaraciones de derechos, divisiones de poderes, gobiernos representativos, reformas de la fiscalidad, la educación y la milicia eran los principales marcadores de modernidad en los que la escritura de la historia debía fijar su atención para dar debida cuenta del acoplamiento nacional respectivo a ese proceso. Si uno repasa hoy obras ciertamente capitales a este respecto de la historiografía académica moderna, como las de Luis Villoro, Miguel Artola y otros historiadores que comenzaron a producir y publicar sus textos más relevantes entre los años cincuenta y sesenta del siglo XX, dos aspectos sobresalen en las mismas. En primer lugar, la perspectiva nacional desde la que se escribieron interesando en ellas el modo en que tal o cual espacio nacional accedió a aquella modernidad marcada 
9

VILLORO, Luis. La revolución de independencia. México-DF: UNAM, 1953; ARTOLA, Miguel. Los origenes de la España contemporánea. Madrid: IEP, 1959.

10

De hecho, el historiador español recién mencionado, Miguel Artola, el más influyente en la segunda mitad del siglo XX sin duda, siguió desde los años sesenta del siglo pasado por esa línea sus investigaciones, dando como resultado un paradigma que establecía en esa división tocquevilliana la arquitectura esencial de la historia moderna y contemporánea de España. Así lo trasladó a un texto de masiva utilización universitaria (Antiguo Régimen y revolución liberal, Barcelona, Ariel, 1978) y al programa de estudios del departamento de Historia Moderna y Contemporánea que fundó y dirigió en la Universidad Autónoma de Madrid.

11 KOSELLECK, Reinhart. Historia social e historia de los conceptos [1986]. En: Historia de conceptos. Estudios sobre semántica y pragmática del lenguaje político y social. Madrid: Trotta, 2012.

12

SEBASTIÁN, Javier Fernández (dir.). Diccionario político y social del mundo iberoamericano. La era de las revoluciones, 1750-1850. Madrid: Fundación Carolina/Sociedad Estatal de Conmemoraciones Culturales/Centro de Estudios Politicos y Constitucionales, 2009. por las revoluciones canónicas de EEUU y Francia. En segundo lugar, el hecho de que parece más un presupuesto que una conclusión la adaptación de cada uno de esos espacios a la modernidad constitucional en el período de la crisis de la monarquía. Tanto en el relato del mexicano como en el del español (lo mismo podría decirse de otros ensayos coetáneos), no es cuestión la modernidad sino únicamente el relato de cómo ésta se fundó y arraigó con la crisis de la monarquía y el primer constitucionalismo. ${ }^{9}$

Tanto para España como para la América española el cruce de ambas líneas de interpretación - formación de naciones que, además, desde su nacimiento se suman a la modernidad constitucional- han marcado de manera indiscutible el discurso historiográfico. Las líneas gruesas de la investigación han ido por el derrotero de mostrar un momento que deja atrás el Ancienne Règime e inaugura el nuevo orden del Estado liberal. ${ }^{10}$ Por supuesto, en momentos recientes que coinciden con la celebración del bicentenario de estos acontecimientos decisivos, dicha estrecha relación entre nacimiento nacional y acceso a la modernidad constitucional ha sido el tópico más utilizado desde el discurso público.

La matización más importante que ha recibido la radicalidad de este modelo interpretativo ha venido desde la adopción de metodologías nuevas de análisis, especialmente la referida a la historia de los conceptos. Como reconoció en varias ocasiones el considerado más relevante "padre fundador" de esta disciplina, Reinhart Koselleck, la idea de un Sattelzeit estaba implícita en buena parte de los trabajos de algunos historiadores, como Otto Brunner o Werner Conze, que habian tratado de delimitar el alcance de las constituciones medievales en la Europa moderna. ${ }^{11}$ La adopción de esa idea de un tiempo largo (1750-1850) en que el mundo occidental fue transformándose - frente a la idea de un cambio súbito, un 1789 - se ha mostrado especialmente fructifera aplicada al espacio iberoamericano. El resultado hasta ahora más importante de esta aplicación, el dirigido por el profesor Fernández Sebastián, muestra, a mi juicio, la comodidad con que la historiografía se ha manejado con esta idea. De la lectura de los materiales aportados por el grupo Iberconceptos podría deducirse que la materia prima de los textos se adecúa mejor a este molde del Sattelzeit que al de equivalentes de un 1789. ${ }^{12}$

Esta aproximación desde una conceptualización distinta del timing de los cambios de fondo en el espacio iberoamericano no ha estado, sin embargo, exenta de una continuidad en cuanto a lo que podriamos denominar "entusiasmo liberal" de la historiografía. Una de las aportaciones que entiendo más sugerentes realizadas recientemente por la historiografia ha consistido en matizar ese sentimiento historiográfico en la interpretación del primer constitucionalismo. Admitiendo que la mera aparición del orden constitucional como marco político fundamental de referencia es por sí un indicio de modernidad, se vienen advirtiendo también aspectos de aquellos primeros experimentos constitucionales que los acotan respecto del paradigma de la "modernidad constitucional". Aspectos tan medulares a ese paradigma como la representación y el sufragio, la liquidación de privilegios y fueros o la división misma de poderes presentarían algunos aspectos contradictorios con el mismo modelo de referencia.

\section{Signos de una modernidad extraña}

Como advirtió en un contundente estudio Antonello Gerbi, desde la Ilustración el pensamiento europeo ha tenido un problema de ubicación e interpretación del mundo hispano en la civilización de la modernidad 
GERBI, Antonello. La disputa del Nuevo Mundo. Historia de una polémica, 1750-1900. México: FCE, 1982.

14

Un epígono, y de seguro no el último de esta tradición de arranque ilustrado: HUTINGTON, Samuel. Who are We? The Challenges to América's National Identity. New York: Simon and Schuster, 2004.

15

La ignorancia normalmente procede a su vez de la indiferencia: de los filósofos ilustrados que participaron vivamente en los debates sobre la significación de España y la América española para la civilización europea prácticamente ninguno conocía América y muy pocos España (CAÑIZARES-ESGUERRA, Jorge. Cómo escribir la Historia del Nuevo Mundo. México: FCE, 2007). La fabricación intelectual de este estereotipo de la monarquía española como un extraño para la civilización moderna se inició, sin embargo, por motivos que no exigian visita de estudios, pues tenian que ver más con la competencia imperial que con el debate cultural: BOTELLA, Eva. Debating Empires, Inventing Empires: British Territorial Claims Against the Spaniards in America, 1670-1714. Journal of Early Modern Cultural Studies, v.10, n1, 2010.

16

La expresión del "otro" Occidente - sin ser original de él- la usó muy afortunadamente a mi juicio Marcello Carmagnani para referirse a los ritmos propios y acompasados a una realidad histórica propia por los que Latinoamérica transitó desde la conquista hasta los siglos XIX y $\mathrm{XX}$ configurando una experiencia histórica alterna a la del occidente "oficial": CARMAGNANI, Marcello. El otro Occidente. América Latina desde la invasión europea hasta la globalización México: Fondo de Cultura Económica, 2004.

17

ALONSO, Gregorio. Prolegomena to Atlantic Catholic Citizenship [paper disponible en http:// sas-space.sas.ac.uk/4135/1/LIA,_Atlantic_ Catholic_Citizenship,_Alonso „_18.04.12.pdf].

18

Es elocuente al respecto el contraste entre el modo en que se socializaron las constituciones de Estados Unidos y de España: MAIER, Pauline. Ratification. The People Debate the Constitution, 1787-1788. Nueva York: Simon and Schuster, 2010 y LORENTE, Marta. El juramento constitucional. Anuario de Historia del Derecho Español, n.65, 1995 occidental..$^{13}$ La idea formulada por Montesquieu y repetida por Edmund Burke de la necesidad de someter a tutela a la monarquía española (lo que finalmente casi consiguió Napoleón) respondía a esta extrañeza que manifestaban las opiniones que a lo largo de la segunda mitad del siglo XVIII se fueron generalizando sobre la monarquía católica. Se trataba de una monarquía de dimensiones descomunales, de un sistema de gobierno a medio camino entre un sultanato, una clericracia y un imperio antiguo. Era la suya una cultura que parecía congelada en el tiempo de El Quijote y se trataba de un espacio, como quiso D'Alembert, precisado de la introducción de matemáticos de contrabando. Eran España y su monarquía, en fin, para el pensamiento ilustrado un espacio de difícil ubicación entre Inglaterra y Turquía. Aunque no es este el lugar, creo que no sería muy difícil demostrar que para el occidente "oficial" esta extrañeza ha continuado hasta hoy. ${ }^{14}$

En esta apreciación - sobre todo cuando se refiere a América - hay, por supuesto, mucho de ignorancia, pero también hay un sustrato de racionalidad indudable. ${ }^{15}$ La racionalidad está en la constatación de que los resultados de la modernidad tal y como ésta se presentó con el constitucionalismo en las primeras décadas del siglo XIX era diferente de la que había cuajado en el "otro" Occidente. Al igual que en los ritmos de las transformaciones sociales y económicas, en el ámbito de la cultura política y, muy especialmente, del constitucionalismo y de la cultura constitucional este espacio mostró algunas singularidades notables. ${ }^{16}$ Entre ellas cabe mencionar, al menos y por la relevancia que tuvieron para la cultura política, el hecho de que se tratara de un constitucionalismo antropológicamente católico, que no produjeran sino tardiamente (a pesar de mostrar plena conciencia de su conveniencia) códigos civiles, que sus ciudadanías se vincularan a la vecindad parroquiana o que se desarrollaran formas de manifiesta radicalidad de la vinculación entre pueblo y soberanía (pronunciamientos).

El rasgo probablemente más compartido y duradero de este primer constitucionalismo en toda la geografía atlántica creo que pone bien de relieve esta bifurcación en los caminos de la modernidad a que me refiero. Se trata de esa profesión de fe que incluyeron todas las constituciones "modernas" hispanoamericanas. No sólo fueron expresos artículos que así de claro lo establecieron, disponiendo la confesión católica nacional y excluyendo la concurrencia de cualquier otra religión, sino que aquellas fueron constituciones antropológicamente católicas. Como lo ha definido recientemente Gregorio Alonso, estariamos ante formas de nacionalismo católico. ${ }^{17}$

Son ordenamientos para los que la forma de establecer la obligación política no proviene de una libre determinación del individuo mediante el referéndum o de la nación mediante la activación de su exclusivo poder constituyente, sino del juramento. Por su propia naturaleza, como es sabido, el juramento no contempla más posibilidad que la aceptación o la exclusión del cuerpo político (e incluso del cuerpo social). Dicho en otros términos, aquella antropología católica no reparaba en absoluto en la existencia de voluntades esenciales de los individuos que pudieran tomar decisiones sobre la forma política sino que ésta se determinaba y se imponía comunitariamente. ${ }^{18}$ Se trata de un constitucionalismo pensado por y para católicos y que no admite la posibilidad de que los ciudadanos católicos puedan determinar libremente sus conciencias.

Esta antropología es la que estaba también detrás de un sistema de representación y elección que, muy habitualmente, suponía una ciudada- 
19

Véase el capítulo XI, firmado por Carlos Garriga, en LORENTE, Marta y VALLEJO, Jesús (coords.). Manual de Historia del Derecho. Valencia: Tiranto lo Blanch, 2012.
20

ROJAS, Beatriz. Los privilegios como articulación del cuerpo político. Nueva España, 1750-1821. En:___ (ed.). Cuerpo político y pluralidad de derechos. Los privilegios de las corporaciones novohispanas. México-DF: CIDEInstituto Mora, 2007

21

De nuevo se trata de un asunto que requeriría muy amplio tratamiento y que aquí no podemos sino apuntarlo. El recorrido es amplio como muestran estudios de los casos aludidos: CALDERÓN, María Teresa y THIBAUD, Clement. La majestad de los pueblos en la Nueva Granada y en Venezuela 1780-1832. Bogotá: Taurus, 2010; VÁZQUEZ, Mario. El imperio mexicano y el reino de Guatemala. Proyecto político y campaña militar. México-DF: FCE, 2010; VERDÓ, Geneviève. L'indépendence argentine entre cités et nation (1808-1821). París: Sorbonne, 2006; SÁBATO, Hilda. Le peuple «un et indivisible». Pratiques politiques du libéralisme "porteño». Les Cahiers ALHIM, n.11, 2005. nía vinculada a la vecindad. Esta condición, la vecindad, se derivaba del cumplimiento cabal de una serie de rituales que respondían estrechamente a esa antropología católica y que necesaria y solamente se producian en ella: condición de feligrés, participación en los ritos y actos públicos de la iglesia católica, adecuación de los modos de vida (desde la vestimenta hasta el matrimonio o el ocio) marcados por una moral católica. Recuérdese que algunas de esas constituciones suspendían ni más ni menos que la ciudadanía por distorsiones en estas adecuaciones.

La continuidad de una antropología católica en el tiempo constitucional originario nos puede permitir explicar el hecho de que se tratara de sociedades en las que se dio la paradoja de una muy temprana previsión de la necesidad del código civil y de una muy tardía aplicación práctica del mismo. ${ }^{19}$ El código civil, como es sabido, es uno, el napoleónico de 1804, al que se han ido adecuando prácticamente todos los producidos con posterioridad. Traducido ya desde 1808, anunciado en cada constitución que se fue haciendo desde 1811, propuesta su necesidad en infinidad de escritos y propuestas constitucionales y políticas, escritos y hasta aprobados códigos por legislaturas estatales como en Zacatecas y Oaxaca, bastante avanzada su redacción en España desde 1823... ¿ ipor qué no se concretó entonces?

Puede que una respuesta a esta paradoja esté precisamente en el hecho de que la modernidad en el Atlántico hispano no estaba moldeada para ser contenida en un código para una sociedad civil sino más bien en una acomodación de una sociedad de cuerpos al orden de la constitución. Como parece insinuar un trabajo de Beatriz Rojas, quizá la modernidad en este occidente estuvo más relacionada con las formas de racionalización de una persistente sociedad corporativa, de ahí que siguiera sirviendo buena parte de su bagaje legal. Un ámbito institucional donde esto podría comprobarse con estudios comparativos es el de los municipios y Estados que bien pudieron actuar como los nuevos contenedores institucionales en los que verter el viejo orden corporativo, dando cumplimiento al ideal ilustrado de una "sociedad bien ordenada"20. Es, en efecto, también signo bastante común de las primeras experiencias constitucionales del orbe hispano que se diera por supuesto que el orden de la nación debía ajustarse al orden de los municipios y de los territorios y no liquidarlo como requisito previo para su afirmación. Ninguna de aquellas experiencias tempranas se pensaron sobre el molde de la republique une et indivisible en el sentido que había establecido ya el preámbulo de la constitución monárquica de 1791, es decir, mediante la desactivación completa de todo el precedente universo corporativo. No lo hicieron siquiera experiencias como la española de 1812 que concibió una nación de dimensiones imperiales o la mexicana, que formalmente conformó un imperio después de su independencia. Casos como los de las provincias rioplatenses o los de Centroamérica son bien elocuentes de que los territorios y municipios (tanto o más que las naciones) fueron los que con más contundencia sostuvieron su relevancia como espacios institucionalizados de racionalización del orden corporativo. ${ }^{21}$

Esto de por sí debería llevar a matizar mucho el carácter de aquel constitucionalismo. En él hay sin ninguna duda dosis de un liberalismo que se desenvolverá a lo largo de la centuria, pero también, y mucho, de crítica ilustrada al mal gobierno que pensaba más bien en reordenar unas piezas desencajadas por la acción del despotismo. En ese empeño no entraba una variación constitucional que partiera de una previa reconceptualización del 
22

Para una discusión en profundidad de esta condición individual determinada social y culturalmente cfr. CLAVERO, Bartolomé. El orden de los poderes. Historias Constituyentes de la Trinidad Constitucional. Madrid: Trotta, 2007

23

Sin entrar a fondo en la cuestión, la apunta en su incisiva consideración crítica sobre el liberalismo en México AGUILAR, José Antonio. La geometría y el mito: un ensayo sobre la libertad y el liberalismo en México, 1821-1970. México-DF: FCE, 2010.

24

SERVÁN, Carmen. Laboratorio constitucional en España. El individuo y el ordenamiento, 18681873. Madrid: CEPC, 2005; LOAIZA, Gilberto. Sociabilidad, religión y política en la definición de la nación. Colombia, 1820-1886. Bogotá: Universidad Externado, 2011; HAMNETT, Brian. Juárez. El benemérito de las Américas. Madrid: Biblioteca Nueva, 2006.

25

VILLACAÑAS, José Luis. Kant en España. El neokantismo en el siglo XIX. Madrid: Verso, 2006.

26

Los trabajos de Julián Viejo iluminan convenientemente el asunto: VIEJO, Julián. Caridad, amor propio y pasiones..., Op. Cit., y Amor propio, interés y religión en la monarquia hispánica de finales del siglo XVIII. En: EI Atlántico lberoamericano y la Modernidad 1750 1850. México-DF: GM Editores, 2012. Algunos de los nutrientes de este constitucionalismo ilustrado pueden seguirse en los estudios preliminares de Bartolomé Clavero a Jean Louis De Lolme. Constitución de Inglaterra. Madrid: CEPC, 1992 y de Jesús Vallejo a Duque de Almodóvar. Constitución de Inglaterra. Madrid: CEPC, 2000. Materiales recopilados pueden hallarse en SARASOLA, Ignacio Fernández. Proyectos constitucionales en España, 17861824. Madrid: CEPC, 2004. Algunas reflexiones adicionales sobre este constitucionalismo ilustrado realizo en PORTILLO VALDÉS, José María. Victorián de Villava: circusntancias e itinerarios. Madrid: Mapfre-Doce Calles, 2009 y en Entre la Historia y la Economía Política: orígenes de la cultura del constitucionalismo. En: GARRIGA, Carlos (coord.). Historia y Constitución. Trayectos del constitucionalismo hispano. México-DF: Instituto Mora, 2010. individuo como un ser autónomo. Entiéndase que me refiero no al sueño de la politología liberal de un individuo asexuado social y culturalmente - que nunca ha existido - sino al que ganaba su autonomía precisamente porque cumplia determinadas condiciones sociales y culturales (masculinidad, propiedad y cultura eurocristiana). ${ }^{22}$ Lo singular del primer constitucionalismo hispano es que tampoco para ese individuo - al que se le supone libre e independiente, es decir, emancipado - está proveyendo autonomía plena, tanta que abarque su propia conciencia: no la consideró pertinente porque por encima de él estableció dos hechos de una contundencia tal que anularon esa posibilidad durante varias décadas de constitucionalismo, la exclusividad de la religión católica y la superioridad nacional. ${ }^{23}$

Así, pues, lo que estaba fallando era la primera pieza, la que dice que el individuo empieza a serlo por ser dueño de su conciencia. ¿Es una casualidad que la aceptación de este aspecto tan medular del liberalismo llegue a este espacio sólo décadas después de ensayado el constitucionalismo? ¿Lo es que sea idéntico su caso al de los códigos civiles y otros aspectos de la modernidad constitucional? En México, como en España o en Colombia, llegaron en escenarios de enfrentamientos civiles que tenían como un motivo central justamente esa descatolización de la política. ${ }^{24}$ La guerra de Reforma en México, la serie de guerras civiles colombianas desde los años sesenta del XIX hasta comienzos del XX, el Sexenio revolucionario en España son escenarios en los que, junto a liberales y conservadores, están enfrentándose dos concepciones de la relación entre antropología católica y política. Registro, matrimonio, educación civiles llegaron sólo cuando lo pudo hacer también el código civil: cuando el individuo autónomo - el que, repito, tenía atributos socio-culturales para serlo que no no eran ni de lejos todos los individuos - pudo sacudirse la tutela de la nación y la determinación de la religión. ¿Será casualidad que Kant haya tardado tanto en ser referencia intelectual en este occidente? ${ }^{25}$

Códigos - el civil ante todo - que se tardan décadas en llegar, formas de sufragio vinculadas a la vecindad parroquiana, asambleas parlamentarias que asumen funciones y procedimientos de los antiguos consejos de la monarquía, corporaciones que siguen dotando de orden a las sociedades gobernadas por las nuevas constituciones, devuelven una imagen no tan nítida como se creyó de la adecuación al paradigma de la modernidad. Desde luego que el problema está no en que estas realidades desentonen con la modernidad sino en el hecho de asumir y aceptar que tal cosa - un paradigma de la modernidad - exista.

Estas constataciones que viene realizando la historiografía, no obstante, exigen un esfuerzo adicional de interpretación de este momento del constitucionalismo originario. Reclama, creo, en primer lugar que se considere una cronología no obcecada con esas cifras mágicas de 1808, 1810 o 1812. Lo que ocurrió antes de esos momentos no sólo fueron unas vísperas del constitucionalismo sino que produjeron ya un constitucionalismo que será muy relevante en el momento en que la crisis de la monarquía urja la necesidad de pensar constitucionalmente. El primer constitucionalismo, en efecto, debe ser visto no sólo como un punto de arranque de una modernidad liberal sino también y diría sobre todo - como el de llegada de una modernidad ilustrada. Aunque falta mucha labor por hacer al respecto, las aportaciones que se vienen realizando al conocimiento del constitucionalismo ilustrado permiten identificar buena parte de sus presupuestos y propuestas en las primeras constituciones que se generaron como reacción a la crisis de la monarquía. ${ }^{26}$ 
27

Es un punto que ha resaltado y defendido como sintoma de una modernidad liberal más allá de lo usual entonces RODRIGUEZ, Jaime E. The Independence of Spanish América. Nueva York: Cambridge UP, 1998.

28

AGUILAR, José Antonio (ed.). El veredicto del pueblo: el gobierno representativo y las elecciones en México, 1809-1846. México-DF: Conaculta-FCE, 2010; SÁBATO, Hilda (coord.). Ciudadanía política y formación de las naciones. México-DF: FCE, 1999.

29

Mal candidato a hacerlo sería habiendo publicado precisamente con ese título un libro sobre los origenes del constitucionalismo en España: PORTILLO VALDÉ, José María. Revolución de Nación. Orígenes de la cultura constitucional en España, 1780-1812. Madrid: CEPC, 2000.
Habría también, por otra parte, que alargar esa cronología del primer constitucionalismo hasta los años treinta del siglo XIX. Fue entonces de manera clara que la crítica al primer constitucionalismo (que en realidad comenzó con la misma experiencia constitucional) puso de relieve, precisamente, las carencias "liberales" del mismo. Aunque pueda parecernos chocante éste fue el caso, por ejemplo, de la crítica contundente que los liberales de los años veinte y treinta hicieron de los primeros sistemas representativos y electorales. Los consideraron errados por lo mismo que nosotros tenderíamos a considerarlos acertados, es decir, por ampliar notablemente el círculo de los llamados a participar en procesos electorales. La especie de "democracia vecinal" que se propuso muy generalizadamente en los primeros ensayos constitucionales del Atlántico hispano no parecía muy adecuada a una ideología que hacía de la propiedad uno de los requisitos sociales de la autonomía. Es a nosotros que nos puede parecer más "liberal" una participación más amplia. ${ }^{27}$ Sin embargo, aquellos liberales sabian sin duda mejor de qué hablaban: la representación de todos los vecinos varones cabeza de familia era más propia para representar una sociedad corporativa que otra civil. Fue a partir del constitucionalismo de los años treinta del XIX que aquella concepción más ilustrada de la ciudadanía de los householders dejó paso a la de los propietarios y fue también entonces que empezó a tomar cuerpo constitucional la crítica de la nación como reunión de pueblos y provincias para dar paso a una idea más estatal de la misma. ${ }^{28}$

Junto a la cronología, la geografía de estos primeros experimentos constitucionales está corrigiendo notablemente el planteamiento originario del paradigma de la modernidad. Lo hace en el sentido de rescatar una comprensión mucho más transnacional de aquel constitucionalismo de lo que se había supuesto, sobre lo que volveré al final de este texto. Utilizo este término sin ninguna intención de vaciar de contenido y relevancia el carácter nacional de aquellos experimentos constitucionales primeros, pero sí con la de advertir sobre la necesidad de entender su énfasis nacional como algo que no era ni política ni moralmente incompatible con la transitividad nacional de aquellos textos. ${ }^{29}$

En efecto, aunque todos aquellos textos - como luego todas las constituciones hasta la fecha - han tenido una referencia incuestionablemente nacional, fueron también constituciones que se transferian con sorprendente facilidad entre naciones. La relevancia de este punto para la historia del constitucionalismo moderno creo que se podrá advertir mejor si la observamos desde la perspectiva temporal larga. Fue el nacionalismo y el principio de nacionalidad quienes habituaron nuestra cultura a pensar el constitucionalismo en términos nacionales estancos, de modo que cada nación precisaba no sólo Estado sino también constitución propia. El mundo actual, que se ha preciado quizá con demasiada ligereza de postmoderno también en este aspecto y de haber superado el Estadonación ha conocido un ensayo de forma política supranacional de más que dudoso éxito todavía - la Unión Europea - que, sin embargo, no ha logrado desarrollar un constitucionalismo propio (de hecho, funciona de manera totalmente "aconstitucional").

El hecho interesante es que hubo un momento, el del primer constitucionalismo, en que sí se dio una mucho más efectiva transitividad constitucional (cultural y también textual) entre naciones. Fue ese el caso de la constitución de Cádiz pero lo mismo ocurrió con otras muchas, como se vio en los espacios americanos que completaron su despliegue nacional con 
Algunas reflexiones al respecto aporto en PORTILLO VALDÉS, José Maria. Identidades complejas en el Atlántico hispano. Los hermanos Guridi Alcocer entre Tlaxcala, España y México. Historias, n.76, 2010.

31

Un reciente estudio brillante sobre la relevancia de los pueblos en el primer constitucionalismo analizada desde la insospechada perspectiva de una diplomacia interna entre ellos es el de ARDILA, Daniel Gutiérrez. Un Nuevo Reino. Geografía política, pactismo y diplomacia durante el interregno en Nueva Granada (1808-1816). Bogotá: Universidad Externado de Colombia, 2010 posteridad a la independencia, como Centro América y Gran Colombia. El estudio de esos casos puede mostrar cómo para una cultura política previa al nacionalismo y el principio de nacionalidad la comunicación constitucional no generaba problema moral alguno. ${ }^{30}$

Todo ello está apuntando hacia la necesidad de una reubicación del primer constitucionalismo en la historia constitucional. Lo hace en el sentido de valorar la novedad de esta experiencia tanto en la reordenación de las piezas tradicionales de gobierno como en la sustitución de las mismas por instituciones que cortaran ataduras con la historia. Un constitucionalismo, en fin, creado por y para católicos, que funcionaba con la legislación civil tradicional sin que el código civil fuera de necesidad tan perentoria, que entendía la nación como suma de pueblos y provincias, que apuntaba a formas de "democracia" vecinal tiene que ser tenido en la historia constitucional como algo sustancialmente distinto de lo que solemos denominar constitucionalismo liberal. ${ }^{31}$

Se trató de un constitucionalismo que también desde el punto de vista de su producción material fue diferente al constitucionalismo posterior. En estrecha sintonía con el discurso de la modernidad se sitúa una actitud historiográfica que ha venido privilegiando la textualidad del primer constitucionalismo sobre otras formas de expresión del mismo. Propio de la modernidad resulta el hecho de que, frente al derecho y los ordenamientos tradicionales, el orden nuevo se exprese en forma de derecho positivo, racional, general y uniforme. Por ello, su historia ha de fabricarse sobre materiales que cumplan tales condiciones, y las constituciones parecen ir como un guante al respecto.

Este supuesto historiográfico ha informado la lectura más habitual del primer constitucionalismo en dos sentidos que quisiera aqui discutir brevemente. En primer lugar predisponiendo un análisis de la textualidad constitucional ávida de hallar en ella los signos inequívocos de la modernidad. No es así en absoluto extraño que incluso se haga uso de la doctrina y la dogmática constitucionales actuales para analizar aquellos textos. Un ejemplo de ello puede verse bien extendido al describir, desde la textualidad constitucional, los engranajes de poderes e instituciones que en se describen en las constituciones tempranas. Antes que cuestionarlos se dan por hechos la división de poderes, la existencia de la administración, la tutela judicial efectiva, el parlamentarismo y otros elementos que caracterizan idealmente la historia del constitucionalismo moderno. Del mismo modo, categorias constitucionales fundamentales como la igualdad o la representación se estudian como si fueran ya parte del bagaje jurídicopolítico de la misma modernidad.

Una aproximación más matizada creo que nos aporta un conocimiento más preciso de la textualidad misma del primer constitucionalismo. Habría que plantearse más decididamente el estatuto mismo de aquellos textos en el sentido de que se trataba seguramente de textos, en primer lugar, menos "absolutos" de lo que solemos suponer pensándolos desde el constitucionalismo moderno. Así como una constitución se entiende hoy un texto fundamental en el sentido de que actúa como una esclusa respecto de todo el ordenamiento (aquello que pasa por ella es válido y lo que no pasa se entiende por este hecho inservible, y para abrir y cerrar la esclusa están los tribunales constitucionales o cortes supremas), las primeras constituciones fueron textos fundamentales en el sentido de que recogían principios básicos de gobierno y de disposición del ordenamiento que afec- 
32

El mejor estudio de conjunto es, en mi opinión, el de PIMENTA, João Paulo Garrido. Estado y nación hacia el final de los imperios ibéricos. Río de la Plata y Brasil, 1808-1828. Buenos Aires: Sudamericana, 2011.
33

Un ejemplo de esta práctica en materia de indudable impacto constitucional: MARTíNEZ, Fernando. Juntas de Censura y jurados. La aplicación peninsular de la normativa gaditana de imprenta (1810-1823) [paper presentado al congreso El nacimiento de la libertad de imprenta. Antecedentes, promulgación y consecuencias del decreto de 1810, Cádiz, 2010].

34

LORENTE, Marta. Las infracciones a la Constitución de 1812. Madrid: Centro de Estudios Constitucionales, 1987 y LORETE, Marta y GARRIGA, Carlos. 1812. La constitución jurisdiccional. Madrid: CEPC, 2007. taba al ámbito de la política. Esto no los convertía en exclusivas fuentes del ordenamiento ni descartaba que otras fuentes siguieran perfectamente activas, como fue el caso del derecho eclesiástico, militar y, en algunos casos, derechos territoriales y municipales.

En segundo lugar, aquel primer constitucionalismo, a diferencia del que generará luego la modernidad liberal desarrollada desde el principio de nacionalidad, se entendió, como he apuntado antes, mucho más transitivo. Una vez desplegado el principio de nacionalidad y desarrollado un constitucionalismo a su medida, la transferencia constitucional resultó más improbable. Sin embargo, el constitucionalismo comenzó a desarrollarse en un mundo que no estaba tallado por aquel principio y que estaba transitando a las naciones desde los imperios atlánticos. La comunicación constitucional en ese escenario era mucho más probable $y$, además, no causaba problema moral alguno, como se reflejó masivamente en un medio tan propio del momento como la prensa. ${ }^{32}$ Lo que los historiadores solemos presentar como la "influencia" de tal texto en tal otro (normalmente con una lectura muy colonial que ve esas transferencias desde espacios metropolitanos a los coloniales) es, en realidad, una característica relevante de un constitucionalismo transitivo.

Unos textos que se entendian fundamentales con respecto al gubernaculum, que eran mucho más transitivos que nacionales (aun estando hechos para naciones) y que no se concebian como textos absolutos, necesariamente tenían que mostrar formas de despliegue más allá de los textos. En efecto, aquel constitucionalismo temprano se nutrió, y mucho, de elementos que transcendian la textualidad constitucional. Un buen ejemplo de ello lo constituye lo que podemos denominar jurisprudencia constitucional difusa. Debemos, de nuevo, tomar distancias respecto de una idea de la constitución como texto absoluto y que, por ello, requiere de una unicidad intransferible en la capacidad jurisdiccional de interpretación del propio ordenamiento. Es lo que - no sin una muy interesante controversia de por medio - logró a principios del ochocientos asentar el Tribunal Supremo de los Estados Unidos y lo que acabaron siendo los Tribunales de Garantías y Tribunales Constitucionales en Europa desde Weimar.

Los textos constitucionales que alumbró la crisis de la monarquía española, por el contrario, obedecieron a una jurisprudencia constitucional difusa. ${ }^{33}$ Por supuesto no existió nada parecido a un tribunal constitucional o de garantías. Tampoco nada similar a las funciones que logró atribuirse el Tribunal Supremo de los Estados Unidos desde 1804. Por término general aquellos textos establecieron dos principios: la defensa esencial de la constitución correspondía a un cuerpo representativo - la misma asamblea representativa de la nación o algún cuerpo especialmente habilitado- pero, al mismo tiempo, la capacidad para iniciar procedimientos de infracción se difundía por todo el cuerpo social de ciudadanos y sus instancias, locales o regionales, de representación. A ello se sumaba una idea también difusa de la responsabilidad personal de los funcionarios públicos en el ejercicio de sus cargos, lo que hacía alusión de manera directa también a posibles infracciones a la constitución. ${ }^{34}$

No es extraño a esta lógica constitucional que llevara aparejada una capacidad también extendida por el entramado institucional que componía el gubernaculum para interpretar el mismo texto constitucional del modo más acorde con las circunstancias propias. Estrechamente unida a la idea de que el texto en sí no era un absoluto normativo, la jurisprudencia 
Casos bien estudiados que lo ilustran: LORENTE, Marta. La Nación y las Españas. Representación y territorio en el constitucionalismo gaditano. Madrid: Universidad Autónoma de Madrid, 2010, cap. 6 y ESCAMILLA, Juan Ortiz. Calleja, el gobierno de la Nueva España y la Constitución de 1812. Revista de Investigaciones Jurídicas, n.20, 1996.

36

GARRIGA, Carlos. Justicia animada. Dispositivos de la justicia en la Monarquía católica. En: LORENTE, Marta (coord.). De justicia de jueces a justicia de leyes: hacia la España de 1870. Madrid: Consejo General del Poder Judicial, 2007.

37

El término de reconstitucionalización, de especial utilidad para entender el ensamblaje entre constituciones y ordenamientos precedentes en CLAVERO, Bartolomé. Nación y Naciones en Colombia entre Constitución, Concordato y un Convenio (1810-2010). En: Revista de Historia del Derecho, n.41, 2011.

38

PERALTA, Víctor. En defensa de la autoridad. Política y cultura bajo el gobierno del virrey Abascal. Perú, 1806-1816. Madrid: CSIC, 2003. constitucional se extendió prácticamente a cada autoridad encargada de aplicar el texto. ${ }^{35}$ Sólo en el caso de que dicha interpretación generara controversia y que la misma no se solucionara en ámbitos locales o regionales se entendería que debía activarse esa capacidad suprema de interpretación del texto reservada a instancias representativas superiores.

Es seguramente este de la jurisprudencia constitucional sobre los textos del constitucionalismo temprano del Atlántico hispano el aspecto en el que más investigación hace falta invertir. Conocemos de manera bastante aceptable los textos y sus circunstancias: cuántos fueron, cómo se hicieron, qué debates se dieron en torno a ellos en aulas parlamentarias y en la prensa, qué alcance tuvieron. Sin embargo, sabemos bastante menos sobre la efectiva aplicación de los mismos. En otros términos: sabemos más acerca de qué fueron esos textos que de cómo fueron. Ahí es donde entra de manera decisiva la idea de una jurisprudencia constitucional difusa.

Ésta comenzó por la realizada en las propias instancias que crearon los textos. Este fue el caso de la constitución de Cádiz que, a dos meses de haber sido promulgada se vio reformada por vía de interpretación por las propias Cortes en un aspecto tan esencial como el derecho de voto en elecciones locales (en un decreto de mayo de 1812 relativo al voto de la gente de color). Pero, sobre todo, aquellos textos fueron "usados" por las autoridades que tenían que implementarlos de acuerdo a una capacidad que entendieron tan propia como lo había sido usualmente y que - como cualquier iudex perfectus habría hecho - implicaba activar su prudentia. ${ }^{36}$ Esto hizo de los textos constitucionales mucho más que los propios textos, pues los convirtieron en algo así como unos desplegables constitucionales donde el principio establecido en el texto podía tener distintos desarrollos jurisprudenciales.

Algunos aspectos del primer constitucionalismo fueron especialmente sometidos a este proceso de re-constitucionalización local, como fue el caso del derecho de voto o del ejercicio de algunas libertades, como la de imprenta. ${ }^{37}$ Pero lo fue, en algunos casos, de la misma constitución, del texto en su integridad. Así ocurrió con el texto de Cádiz en América: su implementación o aplicación parcial dependió de unas autoridades que ni siquiera estaban reguladas por el propio texto, como fueron los virreyes que, aunque reconvertidos en jefes políticos del distrito provincial de la capital, siguieron actuando y, tanto en Perú como en Nueva España, decidiendo sobre la aplicabilidad del texto gaditano. ${ }^{38}$

Si miramos no solamente a estos casos más gruesos de interpretación del texto sino, sobre todo, a una jurisprudencia local que tuvo sobre la marcha que decidir cuestiones de tanto calado como la institucionalización constitucional (nuevos cuerpos locales y regionales, nuevas magistraturas, etc.), la adjudicación del derecho electoral o el reconocimiento de libertades es muy posible que tengamos una imagen más real de un primer constitucionalismo que se pensó para ser texto y seguir siendo jurisprudencia. 